\title{
An Analysis of Three Inflection on Four Economic Phases in the Thetical Economics and the Antithetical Economics
}

\author{
Eizo Kinoshita and Takafumi Mizuno \\ School of Urban Science, Meijo University, Gifu, Japan
}

\begin{abstract}
In this article, we describe Kinoshita's macroeconomic scheme that is Thetical economics and Antithetical economics on four economic phases. Especially, we focus on transitions among the phases. Four economic phases are Thetical economy, Bubble economy, Bubble collapse economy, and Antithetical economy. We give important roles in the description to bubbles. Occurrence and collapse of bubble cause the transitions of economic phases. So explanations of detailed mechanisms of the bubbles are in the article. We try to show them by varying of the consumption propensity.
\end{abstract}

Keywords: Macroeconomics, bubble economy, thetical economics and antithetical economics.

\section{Introduction}

Our study stands on reflect on capitalistic country's past, especially recessions of the United States and Japan.

Keynes constructed his economics to analyze and to overcome the great recession of United States in 1930's. People thought that efficiency of markets makes them be prosperity. But many unemployed people remained in actual markets. Keynes researched why Adam Smith's the hand of God does not work, and he found the inefficiency in labor markets of United States with his macroeconomic research scheme. Throughout his study, he produced modern tools for macroeconomics: macroeconomic models and effective demands. By fruit of his study, we obtain validations to controlling markets. Controlling by government of the United States actually overcame the recession.

Although we had wisdom and tools for controlling markets, we have got a recession again; the Heisei recession in Japan has begun. The recession gives

Corresponding author: Eizo Kinoshita, professor, research fields: macroeconomics, OR, decision making.
Japan lost twenty or lost thirty years since 1990's. Japanese government has taken many acts of fiscal stimulus based on macroeconomics. But Japanese economy is still in the recession.

Meanwhile, next recession has attacked the global economy since 2008. Sub-prime loan problem in the United States caused the recession, and the recession has been affecting to the world. Countries have faced to serious situations which could have threatened its existence by the worldwide crisis. Of cause, the countries have taken measures to avoid the recession. People now have communication technologies and can obtain information of the whole world. Moreover, the countries have shared experience of Japanese recession. But their measures do not work.

Why they still fall in traps? Is there are lacks of macroeconomics? Kinoshita found the reason through his research for bubble economies, and he stated that lack of macroeconomics does not cause the recession. He pointed out that we cannot overcome the recession because we do not know existence of two economics: Thetical economics and Antithetical economics. There are two economics in the markets and we have to use them corresponding economic phases. If we ignore 
them, then we cannot predict that our economic analyses or market controls will work well or will not. In 1930's, Keynes' approach, which is acts on Antithetical economics, worked well because the United States was in an economic phase which suitable for Antithetical economics. And in economic expansion after World War II, monetary policy, which is act on Thetical economics, worked well because the world in an economic phase suitable for Thetical economics. But now, the countries adopt acts of Thetical economics, although they are in an economic phase suitable for Antithetical economics.

In this article, we first describe what Kinoshita's scheme of macroeconomics is. The scheme consists of two economics: Thetical economics and Antithetical economics. Each economics has suitable economic phases in which the economics is valid. These economic phases construct economic cycles and we have to use Thetical economics and Antithetical economics alternately. Next, we describe what the economics phases are and analyses on their inflection points. A trigger of drastically change of economic phases is occurrence of bubble economy and its collapse in Kinoshita's model. Last, we describe a mechanism of how bubbleoccurs and how it collapses, and what is the trigger.

\section{Thetical Economics and Antithetical Economics on Four Economic Phases}

Kinoshita had his insight into gaps between markets in macroeconomics and actual markets. He fills the gaps with representing markets as economic phases. At first, he built two economic phases: Thetical economy, and Antithetical economy. They are, easy to say, markets' states which are in prosperity and are in recession respectively. His unique idea is that he represents rationalities of economic agents on each economic phase and he uses OR's linear programming techniques for its mathematical expressions. Rationalities are micro model of macroeconomics. In macroeconomics, researchers assume that economic agents' actions are rational and the rationality is expressed in any sentences. Kinoshita gives the concrete models of them by providing mathematical formulae. So he rearranges economic theories and policies into two economic phases and clarifies when they are valid. They are arranged into table, and their dualities arise (see Table 1).

A term "economics" is a set of theories or policies for economy. Kinoshita rearranges theories of economics. A set of theories that are valid and work well in Thetical economy is Thetical economics. A set of theories that are valid and work well in Antithetical economy is Antithetical economics.

To describe mechanisms of more abnormal state in economies, which is bubble, Kinoshita prepares two economic phases: Bubble economy and Bubble collapse economy. So there are four economic phases in Kinoshita's economic scheme. A cycle of economy is a sequence of the four economic phases, which are

Table 1 Theories and policies for two economic phases: Thetical economy and Antithetical economy.

\begin{tabular}{|l|l|l|}
\hline Theories and policies & In Thetical economy & In antithetical economy \\
\hline Law & The invisible hand of God. & Fallacy of composition. \\
\hline Corporations' rationality & Maximization of their profit. & Minimization of their debt. \\
\hline Governmental action & Financial reform. & Increasing public spending. \\
\hline Say’s law & Supply creates demand. & Not effective. Results in insufficient demand. \\
\hline Effective demands & Not effective. Crowding out may occur. & Demand creates supply. \\
\hline Monetary policy & Effective. & Not effective. Corporations do notborrow money. \\
\hline Financial policy & Not effective. & Effective. The government is the biggest consumer. \\
\hline Interest rate & Normal rate (inflation). & Ultra-low rate (deflation). \\
\hline Unemployment & None. & Present. \\
\hline Savings & Savings will be investments. & Savings will not be invested. \\
\hline
\end{tabular}


Thetical economy, Bubble economy, Bubble collapse economy, and Antithetical economy.He claims that bubbles play important roles in all macroeconomic cycles. So his macroeconomics has detailed analyses of mechanisms of transitions from Bubble economy to Bubble collapse economy.

\section{A Model of Rationalities of Economic Agents}

Economics' researchers are modeling economic agents. Economic agents are nation people, corporations, or governments. Accumulations of their activities construct macroeconomic indices.

Researchers model these agents as objects that have well-disciplined, act rationally, and they can obtain all information of markets. Of course, the model is quite unrealistic, but macroeconomics stands on the model. We cannot understand any economic statistics or its observations without the model.

Kinoshita modeled a rationality of economic agents using representations of OR's linear programing. He refers to his model as "managements."In this article, we refer to the model as micro model.

In Thetical economy, a rationality of a corporation is represented as

$$
\max \sum_{j \in \text { Produts }} c_{j} x_{j}
$$

s.t.

$$
\forall i \in \text { Items, } \sum_{j \in \text { Products }} a_{i j} x_{j} \leq b_{i}
$$

Where Products is a set of products which are made by the corporation, and Items is a set of items which are materials of products or accounting subjects when the corporation produces its product.In other words, the corporation consumes items of Items, and produces products of Products. $x_{j}$ is an amount of a product $j$ of the corporation, $c_{j}$ is profit of one unit of the product $j . a_{i j}$ is an amount of the item $i$, the corporation needs the amount of $i$ when the corporation produces the product $j . b_{i}$ is limit of debt for an accounting subject $i$.A cost of producing a product $j$ is

$$
\operatorname{cost}(j)=x_{j} \sum_{i \in \text { Items }} a_{i j}
$$

The sum of the term $\sum_{j \in J} c_{j} x_{j}$ in the Eq. (1) for all corporations is the gross domestic product $Y$, which equals tothe supply, in macroeconomics. While the term $\sum_{j \in \text { Products }} a_{i j} x_{j}$ in the Eq. (2) is classified into the consumption $C$ or into the investment $I$.The classification depends on kinds of the corporation and kinds of the accounting subjects of $i$.

In Antithetical economy, a rationality of a corporation is represented as

$$
\min \sum_{i \in \text { Items }} u_{i} b_{i}
$$

s.t.

$$
\forall j \in \text { Proeucts, } \sum_{i \in \text { Items }} u_{i} a_{i j} \geq c_{j}
$$

Where $u_{i}$ is a mortgage rate or an interest rate of an accounting subject $i$.

\section{Three Inflection Points on Four Economic Phases}

Now, we describe below in detail of three inflection points of transitions of economics phases. The consumption propensity, which is denoted inain this article, plays an important rolein our descriptions.

In studies of macroeconomics, the variable $a$ is often treated as an exogenous variable.In this article, we assume the variable $a$ is an endogenous variable, and we describe inflection points with varying the variable.

Structures of the variable ahave been analyzed by researchers who study consumption functions or preference functions. There are many concrete models of consumption functions, and there are many procedures to detect preference functions of individuals. We put a simplest assumption that there is a special level in a market. And the consumption propensity depends on the rate of the supply $Y$ to the level.Closing the supply to the level increases the consumption propensity. 
(1) From Thetical economy to Bubble economy

We describe the first inflection point which is transition from Thetical economy to Bubble economy.

The supply $Y$ creates demands in Thetical economy.

$$
\begin{gathered}
Y \equiv C+I, \\
C=a Y
\end{gathered}
$$

Where $C$ is nationaldemands, and $I$ is investments. This is a simple macroeconomic model.

In the start of Bubble economy, a level of supply $Y_{g}$ appears. The level $Y_{g}$ is higher than the supply $Y$.The consumption propensity $a$ depends on the level;

$$
a=\frac{Y}{Y_{g}}
$$

Increasing $Y$ increases the consumption propensity. From a view with the micro model, growing the consumption propensity beyond 1 needs a condition; there is a special product $k$ which holds

$$
\exists k \in \text { Items } \cap \text { Products and } b_{k} \rightarrow \infty
$$

A term $\sum_{j \in \text { Products }} a_{k j} x_{j}$ of all corporations are added into the consumption $C$ in macroeconomics.

(2) From Bubble economy to Bubble collapse economy

When the supply $Y$ exceeds the level $Y_{g}$, the consumption the propensity $a=Y / Y_{g}$ is larger than 1.Then the bubble collapses. The mechanism of bubble collapse and how the coefficient $a$ works is described later in the article.

The level $Y_{g}$ acts as an upper limit of the supply $Y$ in the Bubble economy.

After the collapse, the economy will be into Bubble collapse economy.

From the view with micro model, a changing value

$$
b_{i}: \infty \rightarrow \text { a finite value }
$$

is trigger of the collapse.

(3) From Bubble collapse economy to Antithetical economy

Under the Bubble collapse economy, investment efficiency $\partial Y / \partial I$ is less than zero, and the consumption propensity is greater than 1 . They are, of course, extraordinary situations.They are canceled throughout the economic phase.

A supply level $Y_{o}$ appears in the economy. The consumption propensity is

$$
a=\frac{Y_{o}}{Y}
$$

The Bubble collapse economy ends with positive investment $I$.Or $Y=Y_{o}$. Then Antithetical economy starts.

Under the Antithetical economy, the micro model is the Eq. (4) with the Eq. (5).Corporations do not try to enlarge their profits. They want to clear their debts. These settlements of their debts are swaps debts of corporations for credits of banks. With a macro view, the exchange does not increase the supply $Y$.

Under Antithetical economy, we can represent the supply $Y$ of macroeconomics as

$$
Y=\min \left\{C+I, Y_{o}\right\}
$$

Even if $Y$ is sufficiently large,

$$
C+I=Y_{o} \text { (constant) }
$$

The micro model is modified as

$$
\min \sum_{i \in \text { Items }} u_{i} b_{i}
$$

s.t.

$$
\begin{gathered}
\forall j \in \text { Products, } \sum_{i \in \text { Items }} u_{i} a_{i j} \geq c_{j} \\
\sum_{j \in \text { Products }} c_{j} x_{j} \leq \text { constant }
\end{gathered}
$$

In other words, corporations make effort to optimize their production activities in Antithetical economy.

\section{A Mechanism of Bursting of Bubbles}

To describe mechanisms of bursting of bubble concretely, we express economic phases in 2-dimenssional $Y$-D space. Thetical economy is a set of points in $Y-D$ space:

$$
\mathrm{T}\left(y_{0}\right)=\left\{(y, d) \mid y>y_{o} \text { and } d \geq y\right\}
$$

Antithetical economy is a set of points in $Y-D$ space: 

Thetical Economics and the Antithetical Economics

$$
\mathrm{A}\left(y_{0}\right)=\left\{(y, d) \mid y<y_{o} \text { and } d \leq y\right\}
$$

Elements of these subsets are affected by $y_{0}$ whose supply is equal to an economic equilibrium point, or a full employment income. In the simple model of macroeconomics, Thetical economy and Antithetical economy are represented by two triangle areas shown in $Y-D$ space (see Fig. 1). In the figure, $Y$ denotes gross domestic product, $D$ signifies demand, and $S$ represents supply. These phases have a relationship of duality.

If a state $(y, d)$ is in Thetical economy, the supply is defined as follows:

$$
Y=C+I
$$

The Say's law is applicable in this case.

While, if a state $(y, d)$ is in Antithetical economy, supply holds a relationship as follows:

$$
Y \geq C+I
$$

The principle of effective demand comes into play in this case.

We define Bubble economy as follows: If a state $(y, d)$ is in Thetical economy and the value $\left[\frac{\partial Y}{\partial I}\right]_{(y, d)}$ is sufficiently large, the state $(y, d)$ is in Bubble economy. And we define the bubble bursting as follows: Whenthere can be seen a partial change, or $\frac{\partial Y}{\partial I}$ from value $\frac{\partial Y}{\partial I}>0$ to value $\frac{\partial Y}{\partial I}<0$, in any state in Bubble economy.

We explain a mechanism of the bubble bursting shown by the simple model of macroeconomics through variations of consumption propensitya. If a state is in Thetical economy, in the simple model of macroeconomics, we obtain arelationship:

$$
\begin{gathered}
\frac{\partial Y}{\partial I}=\frac{\partial C}{\partial I}+1 \\
\frac{\partial C}{\partial I}=a \frac{\partial Y}{\partial I}
\end{gathered}
$$

Now, we deduce as follows:

$$
\frac{\partial Y}{\partial I}=\frac{1}{1-a}
$$

Thus, we can describe a mechanism of the bubble bursting through the behavior of exogenous variable $a$ : (1) first, an economy of real world is demonstrated in a Thetical economy; (2) the consumption propensitya increases and comes close to 1 , and the state is in Bubble economy; (3) the consumption propensity $a$ surpasses 1 , resulting in bubble bursting $\left(\frac{\partial Y}{\partial I}>0 \rightarrow \frac{\partial Y}{\partial I}<0\right)$; and (4) the value $\frac{\partial Y}{\partial I}$ is sharply down, and an economy of real world be in Antithetical economy.

In our definition, Bubble economy is different from economic growth. A concept of economic growth based on the simple model of macroeconomics is demonstrated in Fig. 3. When the investment increases $(\Delta I)$, the equilibrium point moves from $A$ to $A^{\prime}$; that is the expanded equilibrium. And the investment increases to $I_{1}$, then the economic equilibrium point moves to $A_{1}$. As a result, the economy expands more, which is accompanied by an increase in consumption.

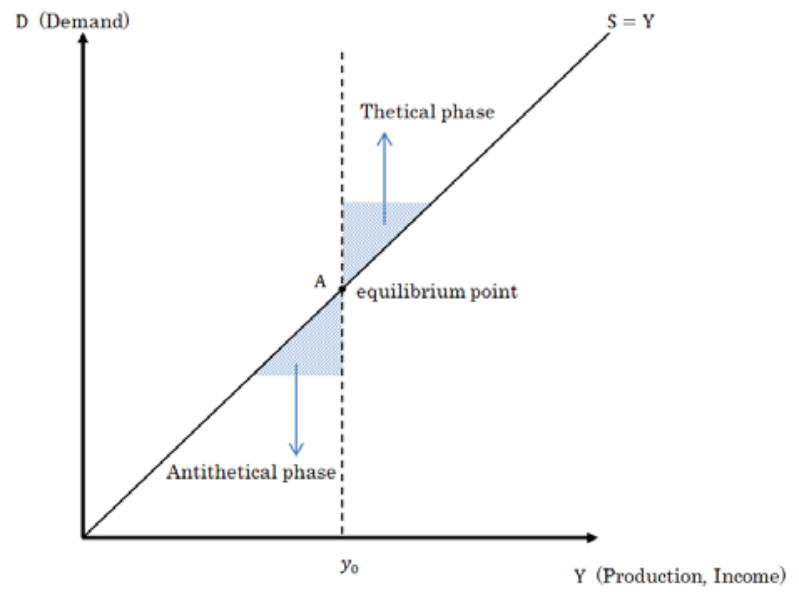

Fig. 1 Thetical economy and Antithetical economyare expressed in $Y-D$ space.

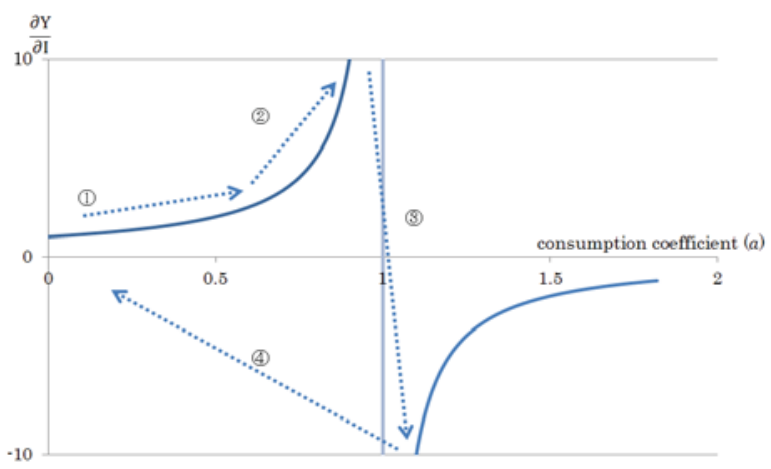

Fig. 2 A mechanism of bubble bursting. 
When corporate capital expenditure grows to $I_{2}$, the economic equilibrium point moves to $A_{2}$, spurring the economy to grow further. During the process of the transition of economic equilibrium points $A \rightarrow A^{\prime} \rightarrow$ $A_{1} \rightarrow A_{2}$, the consumption propensity $a$ is constant in the demand function.

$$
D=a Y+I
$$

When the consumption propensity $a$ is 0.9 in the simple model, for instance, the multiplier effect isexpressed as follows:

$$
\frac{1}{1-a}=\frac{1}{1-0.9}=10
$$

This means that economic growth with the multiplier effect is 10 times (see Fig. 3). We define this type of economic expansion as "economic growth”. We hope readers will remember the definition.

An increase of demand in private sector, during the process of economic growth, may prompt not only companies to expand capital expenditure, but also individual consumers to engage in speculation. In the United States, for example, even a shoeshine boy purchased stocks for speculation during the 1920s. In Japan, housewives, elderly people, and even students engaged in speculation during the so-called Heisei Bubble of the early 1990s. The housing bubble of the United States occurred as an increasingly large number of low-income earners started taking out sub-prime loans after 2005, before house prices in the United States began their steep decline, which triggered the sub-prime crisis in 2008. It was another example of speculative behavior by common folks in the United States. In such a state, the consumption propensity $a$ in the demand function $D=a Y+I$ is infinitely close to 1 . As a result, its economic effect, or multiplier effect, represented by $1 /(1-a)$ in the simple model of macroeconomics, grows without limit. Under such circumstances, the economy expands infinitely, even without an increase in corporate capital expenditure. Our definition of Bubble economy expresses such a state without abnormally high investment effect.

We demonstrated a bubble economy in Fig. 4. The economy expands when the consumption propensity of individual consumers is closer to 1 , even without an increase in corporate investment in facilities. And the economic equilibrium point moves from $A^{\prime}$ to $A_{1}$, and to $A_{2}$. This is the state of Bubble economy.

Bubble economy is often mistaken to be "an outstanding state of economy". History shows that once an individual gets a forbidden state of "a bubble economy”, his or her enthusiasm for speculation tends to be accelerated. During "the Tulip mania” in the first half of the 17th century in the Netherlands, the fad became so excessive that the price of a single tulip bulb rose as high as the price of a house. However, once the consumption coefficient of this "forbidden

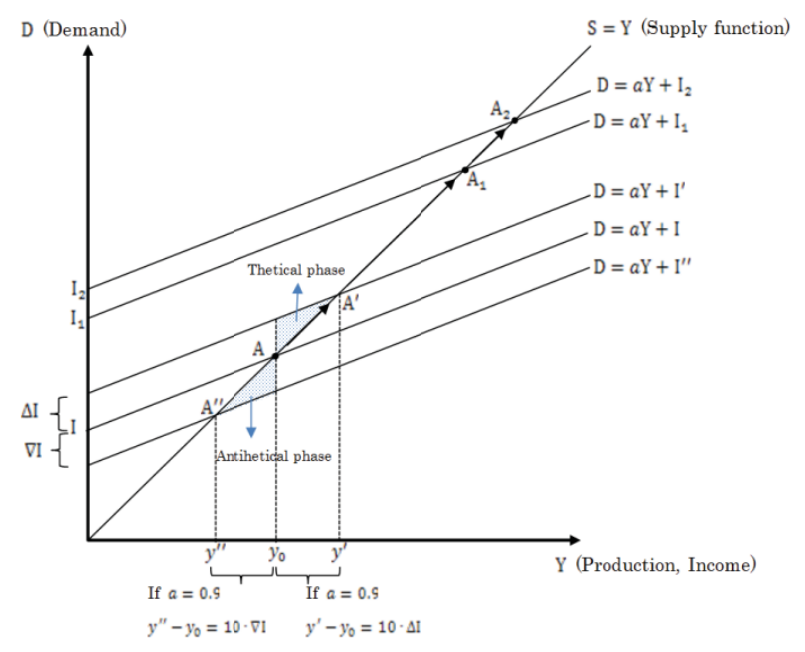

Fig. 3 Economic growth.

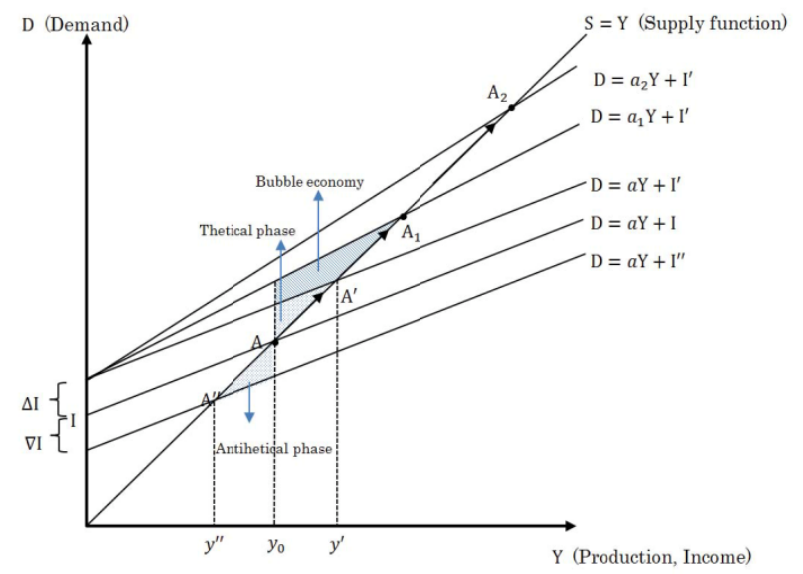

Fig. 4 Bubble economy. 
state of bubble" becomes marginally above 1 , the bubble bursts. The process is shown in Fig. 5 .

If the consumption coefficient $a$ is 1.1, for instance, in the simple model, it turns out to be as follows:

$$
\begin{aligned}
& Y=C+I \\
& C=1.1 Y
\end{aligned}
$$

The solution for the simultaneous equations is as follows:

$$
Y=-10 I
$$

It means that when consumption coefficient grows larger than 1 , and corporate capital expenditure increases by a unit $\Delta I$, the economic equilibrium point falls sharply, and the bubble bursts as shown in Fig. 5. The economic equilibrium point moves from $A$ to $A^{\prime}$ in this case. Once people come to recognize this downturn, they tend to refrain from economic activities, which include not only speculation but also consumption. As a result, the overall consumption of the economy shrinks back, and the consumption coefficient marks less than 1 .

After the collapse of a bubble economy, consumption activities return to normal. As a result, however, the economy suffers a great lack of demand as shown in Fig. 6. We define this state "collapse of a bubble economy" as is shown in section three, in which we described the bubble bursting.

As shown in Fig. 5, private-sector demand for capital falls sharply. Companies stay away from capital expenditure because investment efficiency goes down to dire levels. In other words, because the value of assets purchased on credit during the bubble period collapses, the efficiency of investment drops below the market interest rate for corporations with debt. As a result, companies discontinue investing in facilities, and shift their business priorities from profit maximization to debt minimization. Meanwhile, due to low investment efficiency, companies stop borrowing money from banks to make investments. Instead, they become intent on paying down debt. As a result, money is tucked away in the banking system.

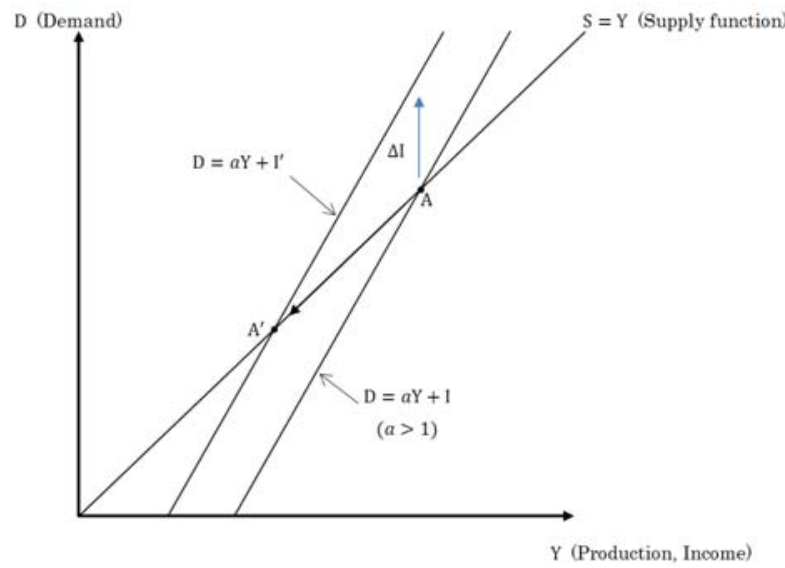

Fig. 5 A mechanism of occurrence and collapse of a bubble economy.

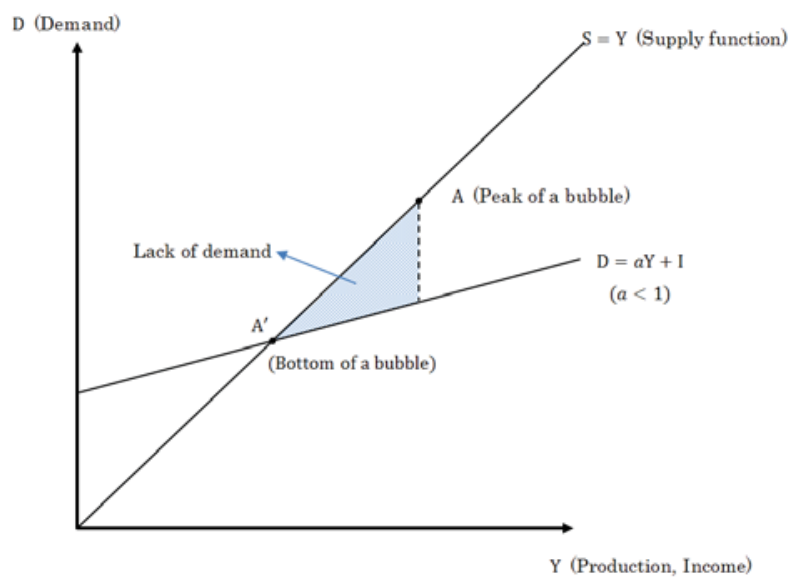

Fig. 6 Lack of demand.

\section{Conclusions}

Each theory of macroeconomics has its suitable situations. Using it in wrong time makes markets confusion. In actual markets, it is not clear which policy we have to adopt and which theory is valid in their states.

In this article, we rearrange theories and policies of economics into two macroeconomics and we simplify markets' state into four phases. A unique point of the scheme is that bubble and its crash play very important roles of transitions among the phases. Then it has detailed mechanism of occurrence and collapse of bubbles. In the mechanism, we choose the consumption propensity and we describe transitions of economic phases by using the value. That is a unique point of our study, too. 
The scheme, Thetical economy and Antithetical economy on four economic phases, are concise and too abstract in macroeconomic view, while they have concrete micro models as economic agents' rationalities. So we can discuss markets in higher abstract levelswhich supported by concrete analyses of the markets.

\section{References}

[1] Kinoshita, E.2011. “A Proposal of Primal and Dual Problems in Macro-Economics.”China-USA Business Review10 (2): 115-24.

[2] Kinoshita,E.2011."Why Bubble Economy Occurs and Crashes? -Repeated History of Economic Growth and Collapse.”Chinese Business Review10 (2): 102-11.

[3] Kinoshita, E.2012. "A Proposal of Thetical Economy and
Antithetical Economy-Mechanism of Occurrence and Collapse of Bubble Economy.”Journal of Business and Economics3 (2): 117-30.

[4] Kinoshita,E., and Mizuno,T.2013.“Analysing Mechanism of an Economic Phase.”China-USA Business Review12 (11): 1025-32.

[5] Kinoshita,E.2015. "Thetical and Antithetical Business Management.” Journal of Business and Economics6 (6): 1086-96.

[6] Mizuno,T., and Kinoshita, E.2016. “An Analysis on Three Inflection Points on Four Economic Phases, Intelligent Decision Technologies2016.”Smart InnovationSystems and Technologies 57: 381-7.

[7] Kinoshita,E., and Mizuno,T.2016. "Economic Rationalities and Governmental Actions on the Thetical Economics and the Antithetical Economics, Intelligent Decision Technologies 2016.”Smart InnovationSystems and Technologies 57: 389-95. 